\title{
Inoculação do feijoeiro associada à adubação foliar com Cobalto e Molibdênio
}

\author{
Bean inoculation associated with foliar fertilization with Cobalt and Molibdenum \\ Inoculación de frijol asociada a fertilización foliar con Cobalto y Molibden
}

Recebido: 15/02/2021 | Revisado: 21/02/2021 | Aceito: 16/11/2021 | Publicado: 25/11/2021

\author{
Gabriele Gonçalves de Mendonça \\ ORCID: https://orcid.org/0000-0001-5659-4109 \\ Universidade Estadual de Mato Grosso do Sul, Brasil \\ E-mail: gabriele.goncalves@outlook.com \\ Francisco Eduardo Torres \\ ORCID: https://orcid.org/0000-0002-6114-0096 \\ Universidade Estadual de Mato Grosso do Sul, Brasil \\ E-mail: feduardo@uems.br \\ Denise Prevedel Capristo \\ ORCID: https://orcid.org/0000-0001-8906-3726 \\ Universidade Estadual de Mato Grosso do Sul, Brasil \\ E-mail: denise_prevedel@hotmail.com
}

\begin{abstract}
Resumo
Acredita-se que o uso de adubação com cobalto e molibdênio associado à inoculação com Rhizobium spp. na cultura do feijão é capaz de favorecer a produtividade, neste sentido, o objetivo deste trabalho foi avaliar o efeito de doses de inoculante e suas interações com cobalto e molibdênio no cultivo do feijão comum. $\mathrm{O}$ experimento foi realizado no campo experimental da Universidade Estadual de Mato Grosso do Sul, em Aquidauana-MS. A cultivar utilizada foi Dama do grupo comercial Carioca. Sendo conduzido em delineamento em blocos casualizados, em esquema fatorial $2 \times 5$, com quatro repetições. Constituido da presença ou a ausência da aplicação foliar de cobalto e molibdênio e doses de inoculante $(0 \mathrm{~mL}, 150 \mathrm{~mL}, 300 \mathrm{~mL}, 600 \mathrm{~mL}, 1200 \mathrm{~mL}$ a cada $50 \mathrm{~kg}$ de sementes $)$. As avaliações realizadas foram matéria verde e seca de nódulos, matéria verde e seca da parte aérea e da raiz, densidade da raiz, número de nódulos por planta, atividade nodular, teor de nitrogênio e fósforo foliar, altura de inserção de primeira vagem, altura de plantas, número de ramificações, número de grãos por vagem, massa de cem grãos e produtividade de grãos. Concluise que a associação entre Rhizobium tropici e adubação foliar, com cobalto e molibdênio no feijão comum, embora não tenha promovido aumento de produtividade de grãos resultou em melhoras nos caracteres agronômicos na cultura. Palavras-chave: Fixação biológica de nitrogênio, Phaseolus vulgaris L., Rhizobium tropici, CoMo.
\end{abstract}

\begin{abstract}
It is believed that the use of fertilization with cobalt and molybdenum associated with inoculation with Rhizobium spp. in the bean crop is able to favor productivity, in this sense, the objective of this work was to evaluate the effect of inoculant rates and their interactions with cobalt and molybdenum in the cultivation of common beans. The experiment was carried out in the experimental field of the State University of Mato Grosso do Sul, in AquidauanaMS. The cultivar used was Dama from the Carioca commercial group. Being carried out in a randomized block design, in a $2 \times 5$ factorial scheme, with four replications. Consisting of the presence or absence of cobalt and molybdenum foliar application and inoculant doses $(0 \mathrm{~mL}, 150 \mathrm{~mL}, 300 \mathrm{~mL}, 600 \mathrm{~mL}, 1200 \mathrm{~mL}$ for every $50 \mathrm{~kg}$ of seeds). The evaluations performed were green and dry matter of nodules, green and dry matter of shoot and root, root density, number of nodules per plant, nodular activity, leaf nitrogen and phosphorus content, height of insertion of first pod, height of plants, number of branches, number of grains per pod, mass of one hundred grains and grain yield. It is concluded that the association between Rhizobium tropici and foliar fertilization, with cobalt and molybdenum in common beans, although it did not promote an increase in grain yield, resulted in improvements in the agronomic traits in the crop.
\end{abstract}

Keywords: Biological nitrogen fixation, Phaseolus vulgaris L., Rhizobium tropici, CoMo..

\section{Resumen}

Se cree que el uso de fertilización con cobalto y molibdeno asociado con la inoculación con Rhizobium spp. en el cultivo de frijol es capaz de favorecer la productividad, en este sentido, el objetivo de este trabajo fue evaluar el efecto de dosis de inoculantes y sus interacciones con cobalto y molibdeno en el cultivo de frijol común. El experimento se llevó a cabo en el campo experimental de la Universidad Estatal de Mato Grosso do Sul, en Aquidauana-MS. El cultivar utilizado fue Dama del grupo comercial Carioca. Realizándose en un diseño de bloques al azar, en un esquema factorial $2 \times 5$, con cuatro repeticiones. Consiste en la presencia o ausencia de cobalto y molibdeno aplicación foliar y dosis de inoculante $(0 \mathrm{~mL}, 150 \mathrm{~mL}, 300 \mathrm{~mL}, 600 \mathrm{~mL}, 1200 \mathrm{~mL}$ por cada $50 \mathrm{~kg}$ de semillas). Las evaluaciones 
realizadas fueron materia verde y seca de nódulos, materia verde y seca de brote y raíz, densidad radicular, número de nódulos por planta, actividad nodular, contenido de nitrógeno y fósforo foliar, altura de inserción de la primera vaina, altura de plantas, número de ramas, número de granos por vaina, masa de cien granos y rendimiento de grano. Se concluye que la asociación entre Rhizobium tropici y fertilización foliar, con cobalto y molibdeno en frijol común, aunque no promovió un aumento en el rendimiento de grano, resultó en mejoras en los rasgos agronómicos del cultivo.

Palabras clave: Fijación biológica de nitrógeno, Phaseolus vulgaris L., Rhizobium tropici, CoMo.

\section{Introdução}

O feijão comum (Phaseolus vulgaris L.) é uma planta anual, herbácea, pertence à família das fabaceae, possui um ciclo que varia de 65 a 115 dias dependo da cultivar e pode ser produzido em todo território brasileiro, possuindo até três safras anuais. A cultura está presente diariamente na mesa do brasileiro com produção principalmente familiar (Ferreira \& Almeida, 2012).

Atualmente, dentro dos seis maiores produtores, o Brasil encontra-se em terceiro lugar, precedido de Myanmar, Índia e acima dos Estados Unidos, México e Tanzânia que juntos produzem 15,3 milhões de toneladas somando 56,99\% do total produzido no mundo (FAO, 2018), Mas o consumo é pequeno nos países mais desenvolvidos e o fato dos grandes produtores mundiais serem também os maiores consumidores gera poucos excedentes exportáveis, limita o conhecimento do mercado. A produção nacional prevista para a safra (2020/2021) é de aproximadamente 3,25 milhões de toneladas, volume semelhante da safra anterior, já tendo sido maior em outros anos, numa área total de 2,95 milhões de hectares (CONAB, 2021).

A cultura do feijão mostra-se bastante exigente em relação aos nutrientes, se destacando o processo de adubação. $\mathrm{O}$ uso de nitrogênio é uma pratica que resulta em ganhos significativos para o desenvolvimento da cultura, porem eleva os custos de produção (Lemos, et al., 2003). A prática da inoculação de sementes com bactérias do gênero Rhizobium possibilita a planta fixar nitrogênio atmosférico podendo diminuir gastos com fertilizantes nitrogenados (Ferreira, et al., 2000).

O êxito da inoculação do feijoeiro depende da qualidade das estirpes em se adaptar ao ambiente que foi inserido. Em ambiente favorável, com pH adequado, acidez tolerável e sem a presença $\mathrm{Al}$, fornece condições apropriadas para a simbiose, formando os nódulos que são capazes de fixar e assimilar o N2 atmosférico (Pelegrin, et al., 2009).

Como alternativa de maximizar os resultados da fixação biológica de nitrogênio no feijão, a utilização de micronutrientes como o cobalto e molibdênio podem apresentar resultados favoráveis. O molibdênio participa diretamente na fixação biológica de nitrogênio, sendo componente essencial de duas enzimas, nitrogenase e redutase, que são indispensáveis para utilização do nitrato promovendo maior acúmulo de $\mathrm{N}$ nas plantas (Berger, et al., 1996).

O cobalto também tem grande importância na FBN exercendo importante papel em processos metabólicos nos nódulos presentes nas raízes, compondo parte da molécula cobalamina, vitamina B12 (Araujo, 2009), atuando também na composição da leghemoglobina, controlando os níveis de oxigênio nos nódulos, de forma que auxilia a enzima nitrogenase, além de compor processos de ativações enzimáticas com participação no metabolismo de carboidratos e proteínas (Marcarello, et al., 2012).

Diante disto, o objetivo deste trabalho foi analisar o efeito das doses de inoculante e a suas interações com a adubação de cobalto e molibdênio na cultura do feijoeiro.

\section{Metodologia}

\subsection{Local do experimento}

O experimento foi conduzido na Universidade Estadual de Mato Grosso do Sul - Unidade Universitária de Aquidauana (UEMS/UUA), setor de fitotecnia, localizado na região de transição entre os biomas Cerrado e Pantanal, nas coordenadas $20^{\circ} 27^{\prime} 20^{\prime \prime} \mathrm{S}$ e $55^{\circ} 40^{\prime} 17^{\prime \prime} \mathrm{W}$ com uma altitude média de 170 metros. 
O solo da área foi classificado como Argissolo Vermelho-Amarelo distrófico de textura arenosa, conforme os critérios do Sistema Brasileiro de Classificação do Solo (Embrapa, 2006), com as seguintes características na camada de 0 - 0,20 m: pH $(\mathrm{H} 2 \mathrm{O})=5,72 ; \mathrm{P}(\mathrm{mg} / \mathrm{dm} 3)=41,3 ; \mathrm{MO}(\mathrm{g} / \mathrm{dm} 3)=21,19 ; \mathrm{K}(\mathrm{cmolc} / \mathrm{dm} 3)=0,49 ; \mathrm{Ca}(\mathrm{cmolc} / \mathrm{dm} 3)=3,05 ; \mathrm{Mg}(\mathrm{cmolc} / \mathrm{dm} 3)=$ 1,$05 ; \mathrm{Ca}+\mathrm{Mg}(\mathrm{cmolc} / \mathrm{dm} 3)=4,1 ; \mathrm{Al}(\mathrm{cmolc} / \mathrm{dm} 3)=0 ; \mathrm{H}(\mathrm{cmolc} / \mathrm{dm} 3)=2,47 ; \mathrm{Al}+\mathrm{H}(\mathrm{cmolc} / \mathrm{dm} 3)=2,47 ; \mathrm{S}(\mathrm{cmolc} / \mathrm{dm} 3)=$ 4,59; $\mathrm{T}(\mathrm{cmolc} / \mathrm{dm} 3)=7,06 ; \mathrm{V} \%=65,01$. O clima da região, segundo a classificação descrita por Köppen-Geiger é do tipo Aw (Tropical de Savana) com precipitação média anual de $1200 \mathrm{~mm}$ e temperaturas médias de $26,2^{\circ} \mathrm{C}$, com inverno seco e verão chuvoso.

Na Figura 1, estão representadas as oscilações de temperatura média e precipitação no período de condução do experimento.

Figura 1. Dados de temperatura média $\left({ }^{\circ} \mathrm{C}\right)$ e precipitação $(\mathrm{mm})$ em decêndios no período experimental. Aquidauana-MS, 2018.

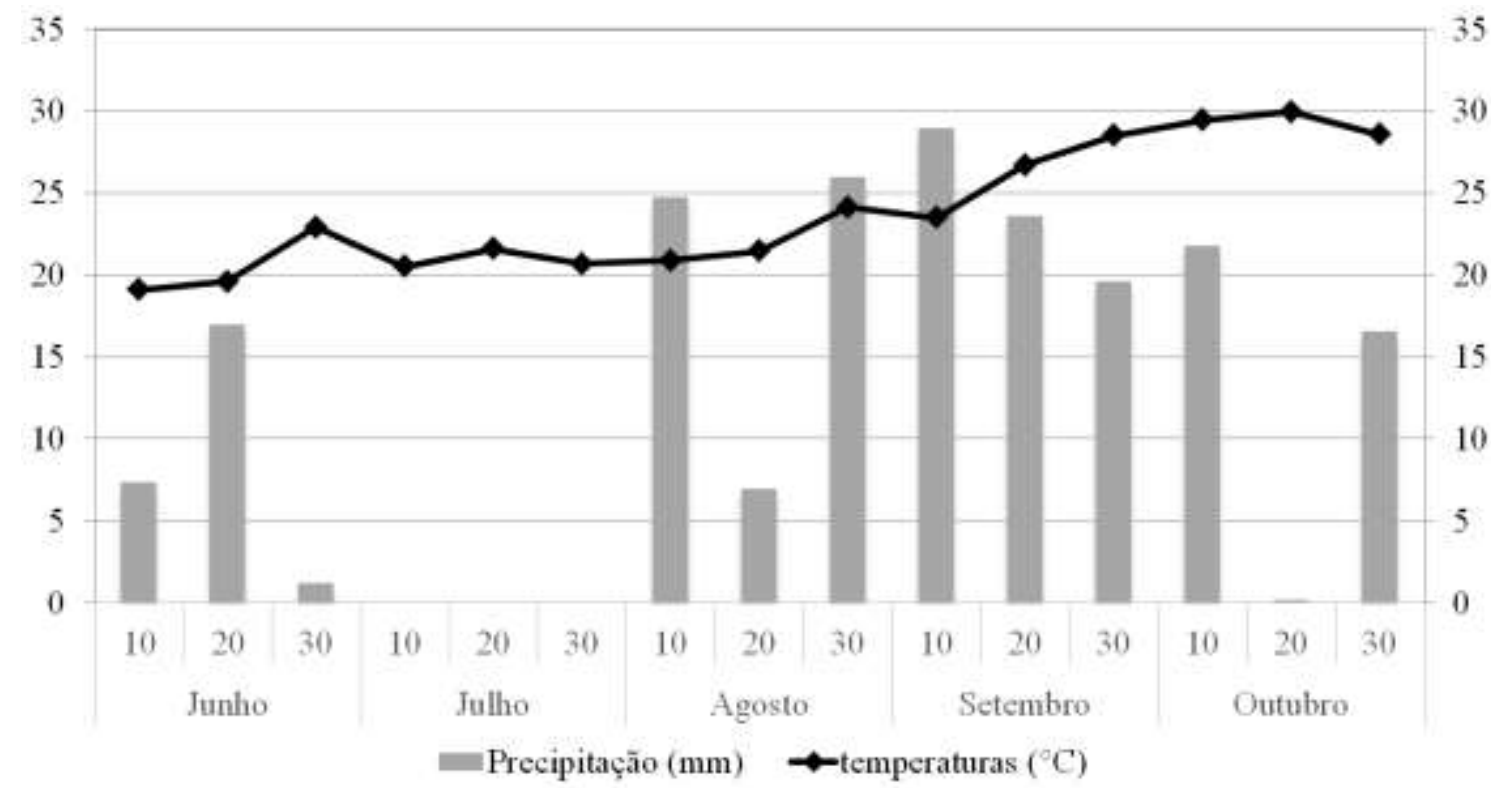

Fonte: Autores.

Durante o preparo da área experimental foi feito a dessecação com o herbicida glyphosate na dose de 2 L.ha-1 do produto comercial e após sete dias foi aplicado o herbicida paraquat, na dose de 2 L.ha-1 do produto comercial, utilizando pulverizador costal. Após a morte do material vegetal, conduziu-se a abertura dos sulcos com a utilização de uma semeadora simples. Nos períodos sem a ocorrência de chuvas (Figura 1) realizou-se irrigação suplementar por meio de irrigação por aspersão convencional.

\subsection{Delineamento experimental}

O delineamento experimental utilizado foi em blocos casualizados, em esquema fatorial $2 \times 5$, com quatro repetições. O primeiro fator foi constituído da presença e ausência de cobalto e molibdênio (Fertilizante absortec copper, via foliar, 15 dias após a semeadura). O segundo fator foram as cinco doses de inoculante $(0 \mathrm{~mL}, 150 \mathrm{~mL}, 300 \mathrm{~mL}, 600 \mathrm{~mL}$ e $1200 \mathrm{~mL}$ a cada 50 $\mathrm{kg}$ de sementes).

A cultivar semeada foi do grupo carioca, Dama, de ciclo médio de 90 dias. Porte prostrado, altura da planta de $50 \mathrm{~cm}$, hábito de crescimento tipo III. Cada parcela foi constituída de sete linhas com cinco metros de comprimento, espaçadas a 0,45 m entre si, considerando as três linhas centrais como área útil para avaliação de produtividade de grãos e demais características 
avaliadas. A semeadura foi realizada manualmente, sendo distribuídas 12 sementes por metro para o estabelecimento de 240.000 plantas.ha-1.

As sementes foram tratadas com fungicida/inseticida piraclostrobina + metil tiofanato + fipronil na dose de 200 mL.100 kg-1 de sementes. As mesmas foram inoculadas com Rhizobium tropici nas doses: $0 \mathrm{~mL}, 150 \mathrm{~mL}, 300 \mathrm{~mL}, 600 \mathrm{~mL}$, $1200 \mathrm{~mL}$ para cada $50 \mathrm{~kg}$ de sementes, de acordo com os tratamentos estabelecidos.

\subsection{Variáveis analisadas}

A matéria verde da parte aérea, matéria seca de parte aérea, matéria verde de raízes, matéria seca de raízes, volume de raiz, atividade nodular, número de nódulos por planta e matéria verde de nódulos foram mensuradas no estádio R6 (florescimento pleno). Foram mensuradas em três plantas que estavam contidas em um monólito (30x30x30 cm), de comprimento, largura e profundidade respectivamente. O monólito foi desfeito com lavagem em água corrente, e separadas em raízes e parte aérea para obtenção da massa da matéria verde. Posteriormente as plantas foram levadas ao laboratório, para secagem em estufa de circulação de ar forçado a $65^{\circ} \mathrm{C}$ por $72 \mathrm{~h}$, para obtenção da matéria seca.

A contabilização dos nódulos presentes no sistema radicular foi feita de forma manual e se obteve o número de nódulos por planta. Para determinação da atividade nodular, foram retirados dez nódulos aleatórios e determinada qual proporção continha a coloração interna rosa, e caracterizados como nódulos ativos.

Para a variável nitrogênio foliar foi coletada a última folha trifoliolada completamente expandida de dez plantas por parcela, quando a cultura estava em estágio R6 (florescimento pleno) (Silva, 2009).

Foram coletadas três plantas por parcela quando as mesmas se encontravam no estádio fenológico R9 (maturação fisiológica). Nessas plantas foram mensuradas a altura de plantas, altura de inserção de primeira vagem, número de ramificações, massa de cem grãos, número de vagens por planta e número de grãos por vagens.

Ainda em R9, foi mensurada a produtividade de grãos. Foram colhidas as três linhas centrais das parcelas. Foi mensurada a massa e a umidade dos grãos, a umidade foi corrigida para 13\%, e a massa extrapolada para kg.ha-1.

\subsection{Análises estatísticas}

Após atendidos os pressupostos da análise de variância (normalidade e homocedasticidade), prosseguiu-se com a mesma. O fator presença e ausência da adubação foi considerado qualitativo e se observada diferença significativa entre as médias prosseguiu-se com o teste de Tukey 5\%. O fator doses de inoculante foi considerado quantitativo, se constatada diferença significativa prosseguiu-se com a análise de regressão. Foram observados os ajustes pelo coeficiente de determinação, escolhendo-se o melhor modelo que descreve os dados. As análises estatísticas foram realizadas utilizando os pacotes Expedes (Expedes: fat2. rbd; Ferreira, et al., 2014) no software R (ver. 3.5.2 Team, 2018).

\section{Resultados e Discussão}

De acordo com a análise de variância, não houve significância isolada em todas as variáveis analisadas para adubação. Já para inoculação houve significância quando avaliado número de nódulos. A interação apresentou significância para massa verde de nódulos, massa verde departe aérea e volume de raiz (Tabela 1). 
Tabela 1. Valores-p da análise de variância para as variáveis número de nódulos (NN), massa verde de nódulos (MVN), massa verde de parte aérea (MVPA), massa verde de raízes (MVR), massa seca de nódulos (MSN), massa seca de parte aérea (MSPA), massa seca de raízes (MSR), volume de raiz (VR) e nitrogênio foliar (N).

\begin{tabular}{cccccccccc}
\hline $\begin{array}{c}\text { Fontes de } \\
\text { Variação }\end{array}$ & NN & MVN & MVPA & MVR & MSN & MSPA & MSR & VR & N \\
\cline { 2 - 4 } & $>0,05$ & $>0,05$ & $>0,05$ & $>0,05$ & $>0,05$ & $>0,05$ & $>0,05$ & $>0,05$ & $>0,05$ \\
Adubaça & $0,02^{*}$ & $>0,05$ & $>0,05$ & $>0,05$ & $>0,05$ & $>0,05$ & $>0,05$ & $>0,05$ & $>0,05$ \\
Inoculação & $>0,05$ & $0,03 *$ & $0,04 *$ & $>0,05$ & $>0,05$ & $>0,05$ & $>0,05$ & $0,00 *$ & $>0,05$ \\
A x I & 42 & 17 & 27 & 47 & 45 & 46 & 37 & 36 & 18 \\
\hline CV $(\%)$ & & & & & & & &
\end{tabular}

$>0,05$ não significativo a 95\% de significância; <0,05significativo a 95\% de significância; CV: coeficiente de variação; A: adubação; I: Inoculação. Fonte: Autores.

A variável número de nódulos foi significativa para o fator inoculação, o que foi interessante, por ser esperado melhor rendimento da cultura em relação à absorção de N. A massa verde de parte aérea se desenvolveu melhor, por exemplo, sendo o nitrogênio um fator que pode ter sido determinante.

Segundo pesquisa, também houve diferença significativa para a número de nódulos por planta, onde algumas estirpes se mostraram superiores. Acreditasse que este fenômeno se deu devido à maior capacidade das estirpes em se adaptar as condições ambientais e se sobressair às espécies nativas no quesito nodulação (Ferreira, et al., 2000). Isso se explicou, pois as estirpes apresentaram diferentes níveis de adaptação às condições ambientais (Herridge \& Danso, 1995).

Em alguns trabalhos notou-se que a massa verde de nódulos de feijão Caupi (Vigna unguiculata (L.) Walp) não diferiu dos tratamentos sem inoculação (Costa, et al., 2011). O autor defende ainda, que não só a variação das doses de inoculante é responsável por promover uma nodulação eficiente, mas também outros eventos como fatores ambientais, tipo de solo e a capacidade de sobrevivência e competição de cada cepa (Depret et al., 2004).

Para MVN submetido a tratamentos semelhantes não foram encontradas diferenças, porém observou que as maiores doses de molibdênio apresentaram uma queda de rendimento (Guareschi, 2009). Isto foi evidenciado em outros trabalhos, que afirmaram que em altas concentrações de molibdato, via foliar, pode ter ocasionado efeito tóxico às plantas (Gris, 2005).

No feijão comum, a inoculação com R. tropici associada a adubação com Mo aumentou o teor de nitrogênio foliar, acúmulo de biomassa vegetal, número de vagens e pesso de 1000 grãos e produtividade na cv. Pérola (Oliveira, et al., 2017). Defende-se que este comportamento seja justificado porque a nitrogenase, enzima sintetizada pelo Rhizobium e responsável pela fixação do N depende de Mo (Hungria, et al., 2007).

Uma planta bem suprida em $\mathrm{N}$ apresenta sistema radicular maior que uma planta deficiente em $\mathrm{N}$ (Cunha, et al., 2010), porque os mecanismos envolvidos no crescimento do sistema radicular estão relacionados com o acúmulo de carboidratos (Brouwer, 1962).

Na Figura 2 é possível observar o ajuste do modelo quadrático para número de nódulos, recebe destaque a dose recomendada do inoculante, por apresentar maior quantia de nódulos por planta. 
Figura 2. Número de nódulos (NN) por plantas submetidas a diferentes doses de inoculante.

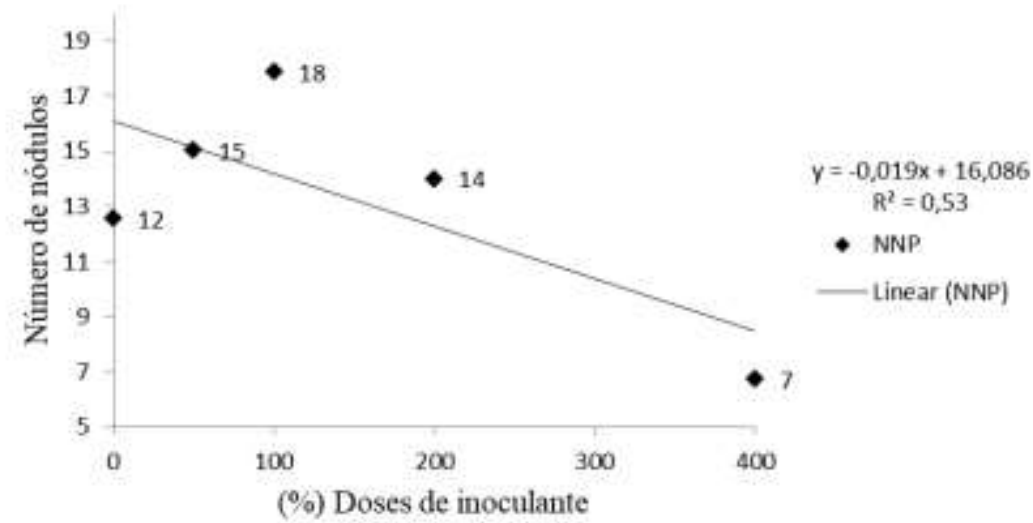

Fonte: Autores.

Mediante aos resultados aqui encontrados, pode-se concluir que o aumento da densidade do inoculante não se mostra eficiente. Em estudos com feijão caupi também ocorreram resultados favoráveis à nodulação quando incrementada com o uso de adubação com Cobalto e molibdênio, onde a mesma se mostrou superior quando adubada. Utilizou-se neste experimento a dose recomendada pelo fabricante do inoculante, pois o autor defende que não seja este um fator que pode ter grande influência para que haja diferença entre os tratamentos (Paulo, 2013).

Uma planta bem nodulada deve apresentar cerca de 15 à 30 nódulos durante o florescimento (Campo \& Hungria, 2002). Oque corrobora com os resultados encontrados em nosso experimento, já que os valores obtidos, que se enquadram dentro do padrão estabelecido pelos autores supracitados, estão próximos à dose recomendada do inoculante.

São muitos os exemplos na literatura onde não se observa efeito da aplicação de molibdênio no número de nódulos, possivelmente porque a adição deste micronutriente pode estar associada com a elevação da eficiência do nódulo, pela maximização da atividade da enzima nitrogenase, e não com a elevação do número de nódulos por planta (Jacob Neto \& Franco, 1989; Alves, 2002).

Em relação à adubação houve significância para os caracteres altura de plantas (AP), altura de inserção da $1^{\circ}$ vagem (AIV), número de grãos por vagem (NGV) e no número das ramificações (NR). Para inoculação, os resultados apresentaram diferença significativa apenas para altura de plantas (AP). Já para a interação A x I, houve diferença significativa somente quando analisado o número de vagens por planta (NV). (Tabela 2)

Tabela 2. Valores da análise de variância para as variáveis Altura de Plantas (AP), Altura de inserção da $1^{\circ}$ vagem (AIV), Números de vagens (NV), Número de Grãos por vagem (NGV), Número de Ramificações (NR), Massa de Cem Grãos (MCG) e Produtividade (PROD) avaliadas em feijão submetidas a diferentes manejos.

\begin{tabular}{cccccccc}
\hline Fontes de Variação & AP & AIV & NV & NGV & NR & MCG & PROD \\
\cline { 2 - 7 } Adubação (A) & 0,02 & 0,03 & $>0,05$ & 0,00 & 0,04 & $>0,05$ & $>0,05$ \\
Inoculação (I) & 0,04 & $>0,05$ & $>0,05$ & $>0,05$ & $>0,05$ & $>0,05$ & $>0,05$ \\
A x I & $>0,05$ & $>0,05$ & 0,04 & $>0,05$ & $>0,05$ & $>0,05$ & $>0,05$ \\
\hline CV (\%) & 21 & 37 & 48 & 21 & 37 & 4 & 22 \\
\hline
\end{tabular}

$>0,05$ não significativo a 95\% de significância; <0,05significativo a 95\% de significância; CV: coeficiente de variação. Fonte: Autores.

A interferência da adubação com cobalto e molibdênio na cultura do feijão comum, não encontrou significância para a 
interação dos micronutrientes, entretanto a pratica resultou em acréscimo no número de vagens e uma tendência no aumento da produtividade conforme aumentada a adubação (Torres, et al., 2014).

Em estudos com inoculação em feijão associada a aplicação de nitrogênio e molibdênio, foi observada ausência de significância, concluindo que não foram efetivas sobre o desenvolvimento e produtividade da cultura. Acreditou-se que este fato ocorreu devido à presença de estirpes nativas de Rhizobium na área, normalmente mais agressivas que a introduzida (Bassan, et al., 2001).

O efeito do molibdênio na cultura da soja e feijão quando inoculadas, encontrou queda na produção de biomassa vegetal das culturas conforme o aumentado às doses de molibdênio via foliar (Guareschi, 2009).

Na figura 3, ao analisar altura de inserção de primeira vagem, as médias obtidas indicam que as plantas que não receberam adubação de cobalto e molibdênio apresentaram valores superiores às plantas que receberam a adubação.

Figura 3. Média de altura da Inserção da $1^{\circ}$ Vagem (AIV) das plantas submetidas a diferentes tratamentos comparadas pelo teste de Tukey a $5 \%$ de probabilidade.

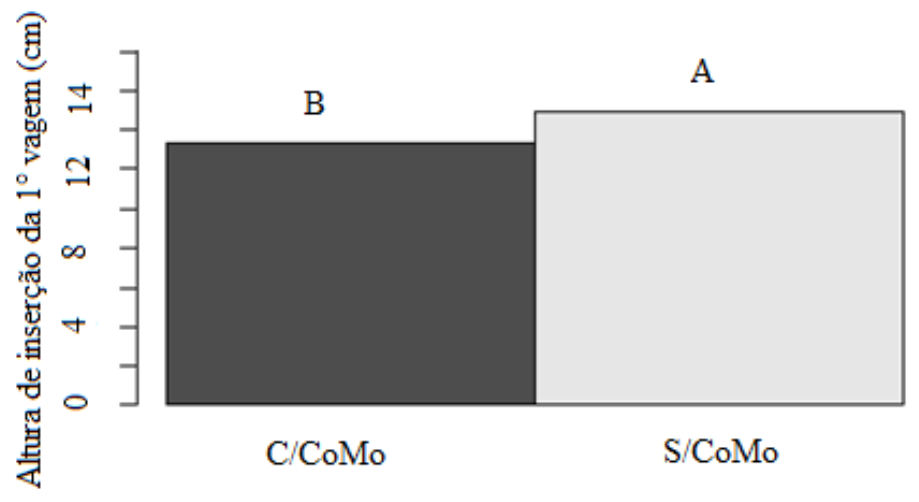

Fonte: Autores.

A importância da altura de inserção da primeira se da por conta da colheita mecanizada, onde vagens com baixa altura de inserção podem não ser colhidas, além de ocasionar contaminação por fungos e ataque de pragas, causando perdas para a cultura (Kappes, et al., 2008).

Em estudos com o feijoeiro de inverno, inoculado e que recebeu adubação em cobertura de molibdênio, a adubação não influenciou na altura de inserção de $1^{\circ}$ vagem nos dois primeiros anos de cultivo. Entretanto as plantas apresentaram, de modo geral, altura superior a $20 \mathrm{~cm}$ (Barbosa, et al., 2010).

Quando avaliado as médias de número de grãos por vagem no que diz respeito à adubação, as plantas que receberam suplementação de cobalto e molibdênio apresentaram média superior quando comparadas as que não receberam (Figura 4). 
Figura 4. Média do número de grãos por vagem (NGV) das plantas submetidas a diferentes tratamentos comparados pelo teste de Tukey a $5 \%$ de probabilidade.

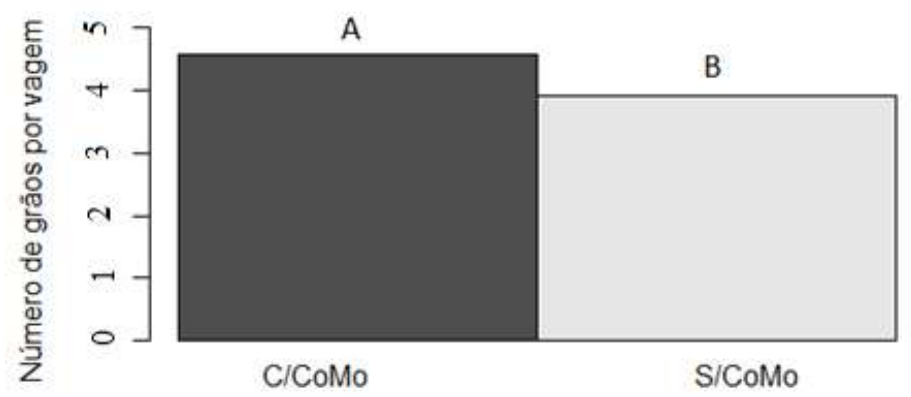

Fonte: Autores.

O número de grãos por vagem está diretamente relacionado com a produtividade da cultura, e uma planta que apresenta maior massa de grãos por, consequentemente será mais produtiva.

Esta característica é fortemente influenciada pela hereditariedade dos genes, sendo pouco influenciada pelos manejos empregados, dependendo das características da variedade que foi estudada (Torres, et al., 2014). Apesar disso, nesse trabalho, a aplicação de cobalto e molibdênio influenciou esse caráter positivamente.

Em estudo semelhante com aplicação de molibdênio via foliar na cultura feijão, verificou-se que a adubação com o micronutriente não diferiu estatisticamente (Oliveira, et al., 2017). De acordo com experimento com adubação molíbdica no feijoeiro, não constataram efeito desse micronutriente nos componentes da produção (número de vagens por planta, de sementes por vagem e massa de 100 grãos) (Ascoli, et al., 2008).

No feijoeiro o número de sementes por vagem é uma característica de alta herdada geneticamente e com pouca influência do ambiente (Andrade, et al., 1998).

Avaliando os valores obtidos para número de ramificações na fonte de variação adubação, as plantas suplementadas com adubação de cobalto e molibdênio apresentaram resultados superiores às plantas que não receberam adubação.

Figura 5. Valores comparados através do teste de tukey a 5\% de probabilidade para a variável número de ramificações.

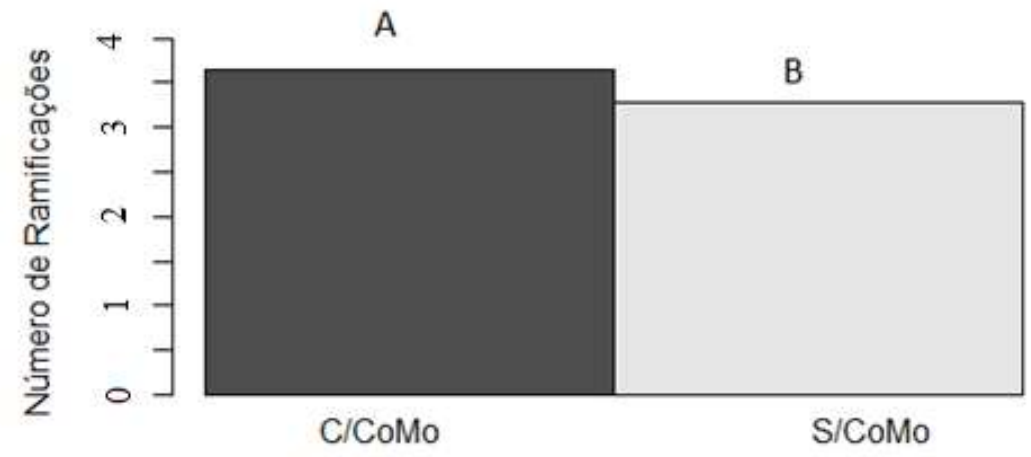

Fonte: Autores.

O número de ramificações compreende a quantidade de estruturas reprodutivas, que consequentemente darão origem ao número de vagens por planta, por isso, quanto maior for o NR, maior será o número de nós e, consequentemente, o número de vagens por planta (Demari, et al., 2015).

Os valores baixos de NR podem ser explicados pela competição por fatores de crescimento como luz, água e nutrientes, devido ao número excessivo de plantas nas linhas, o que vai diminuir a disponibilidade de fotoassimilados, fazendo 
com que as plantas produzam menor número de ramificações e menor número de nós (Costa, 2013).

\section{Conclusão}

Conclui-se que a utilização de inoculante, cobalto e molibdênio no feijoeiro comum, contribui para acréscimos nos caracteres agronômicos da cultura, o que indica que seu desenvolvimento seja superior do que quando não utilizado, porém isso não ocorreu para a produtividade.

\section{Referências}

Alves, J. M., Guimarães, E. C., Alves, J. S., \& Jacob Neto, J. (2002). Aplicação foliar de molibdênio em caupi (Vigna unguiculata (L.) Walp). Revista Universidade Rural, 22(2), 193-197.

Andrade, M. D., Diniz, A. R., Carvalho, J. D., \& Lima, S. D. (1998). Resposta da cultura do feijoeiro à aplicação foliar de molibdênio e às adubações nitrogenadas de plantio e cobertura. Ciência e Agrotecnologia, 22(4), 499-508.

Araujo, R.S. Fixação biológica do nitrogênio em feijão. In: Araújo, R.S.; Hungria, M. (Ed.) Microorganismos de importância agrícola. Brasília: Embrapa-SP, $1994,236 \mathrm{p}$

Ascoli, A. A., Soratto, R. P., \& Maruyama, W. I. (2008). Aplicação foliar de molibdênio, produtividade e qualidade fisiológica de sementes de feijoeiro irrigado. Bragantia, 67(2), 377-384.

Barbosa, G. F., Arf, O., Nascimento, M. S. D., Salatiér, B., \& Freddi, O. D. S. (2010). Nitrogênio em cobertura e molibdênio foliar no feijoeiro de inverno. Acta Scientiarum. Agronomy, 32(1), 117-123.

Bassan, D. A. Z., Arf, O., Buzetti, S., Carvalho, M. A. C., Santos, N. C. B., \& Sá, M. D., \& Guerreiro neto, G. (2001). Inoculação de sementes e aplicação de nitrogênio e molibdênio na cultura do feijão de inverno: produção e qualidade fisiológica de sementes. Revista Brasileira de Sementes, 23(1), 76-83.

Berger, P. G., Vieira, C., \& Geraldo, A. D. A. (1996). Efeitos de doses e épocas de aplicação do molibdênio sobre a cultura do feijão. Pesquisa Agropecuária Brasileira, 31(7), 473-480.

Bortels, H. (1930). Molybdän als Katalysator bei der biologischen Stickstoffbindung. Archiv für Mikrobiologie, 1(1), $333-342$.

Brouwer, R. (1962). Influências nutritivas na distribuição da matéria seca na planta (nº 205).

Bulen, W. A., \& LeComte, J. R. (1966). The nitrogenase system from Azotobacter: two-enzyme requirement for N2 reduction, ATP-dependent H2 evolution, and ATP hydrolysis. Proceedings of the National Academy of Sciences of the United States of America, 56(3), 979.

Campo, R. J., \& Hungria, M. (2002). Importância dos micronutrientes na fixação biológica do N2. Informações Agronômicas, (98).

Coelho, C. M. M., Zilio, M., Souza, C. A., Guidolin, A. F., \& Miquelluti, D. J. (2010). Características morfo-agronômicas de cultivares crioulas de feijão comum em dois anos de cultivo. Semina: Ciências Agrárias, 31(1), 1177-1186.

Coêlho, J. D. (2018). Produção de grãos: feijão, milho e soja.

CONAB. Companhia Nacional de Abastecimento, Acomp. safra bras. grãos, v. 8 Safra 2020/21 - Quinto levantamento, Brasília, fevereiro 2021.

Costa, É. D. (2013). Arranjo de plantas, características agronômicas e produtividade de soja.

Costa, E. M., Nóbrega, R. S. A., Martins, L. D. V., Amaral, F. H. C., \& Moreira, F. M. D. S. (2011). Nodulação e produtividade de Vigna unguiculata (L.) Walp. por cepas de rizóbio em Bom Jesus, PI. Revista Ciência Agronômica, 42(1), 1-7.

Cunha, F. F. D., Ramos, M. M., Alencar, C. A. B. D., Martins, C. E., Cóser, A. C., \& Oliveira, R. A. D. (2010). Sistema radicular de seis gramíneas irrigadas em diferentes adubações nitrogenadas e manejos. Acta Scientiarum. Agronomy, 32(2), 351-357.

Demari, G. H., Souza, V., Carvalho, I. R., Nardino, M., \& Follmann, D. (2015). Feijão em época não preferencial submetido a doses de nitrogênio e seu impacto nos caracteres agronômicos. Enciclopédia Biosfera, 11(21).

Depret, G., Houot, S., Allard, M. R., Breuil, M. C., Nouaïm, R., \& Laguerre, G. (2004). Long-term effects of crop management on Rhizobium leguminosarum biovar viciae populations. FEMS Microbiology Ecology, 51(1), 87-97.

Embrapa, S. (1999). Sistema brasileiro de classificação de solos. EMBRAPA Solos.

FAOSTAT. Crops. Disponível em: http://www.fao.org/faostat/en/\#data/QC.

Ferreira, A. N., Arf, O., Carvalho, M. A. C. D., Araújo, R. S., Sá, M. E. D., \& Buzetti, S. (2000). Estirpes de Rhizobium tropici na inoculação do feijoeiro. Scientia Agricola, 57(3), 507-512.

França, M. G. C., Araújo, A. P., Rossiello, R. O. P., \& Ramos, F. T. (2008). Relações entre crescimento vegetativo e acúmulo de nitrogênio em duas cultivares de arroz com arquiteturas contrastantes. Acta Botanica Brasilica, 22(1), 43-49. 
Frigo, G. R. (2013). Feijão caupi submetido à inoculação com rizóbio e cultivado em latossolo do cerrado matrogrossense.

Griffiths, B. S., \& Fitter, A. H. (1999). Plant root proliferation in nitrogen-rich patches confers competitive advantage. Proceedings of the Royal Society of London B, 26, 431-435.

Gris, E. P., Conte, A. M., \& Oliveira, F. F.de. (2005). Produtividade da soja em resposta à aplicação de molibdênio e inoculação com bradyrhizobium japonicum. Revista Brasileira de Ciência do Solo, 29, 151- 155.

Guareschil, R. F., \& Perin, A. (2009). Efeito do molibdênio nas culturas da soja e do feijão via foliar. Global Science and Technology, v. 02, n. 03, p.08 - 15, set/dez.

Guidorizzi, F. V. C. (2019). Exigência de nitrogênio e manejo da adubação nitrogenada em cultivares de feijão-comum de ciclo precoce. Faculdade de Ciências Agronômicas da UNESP. Tese (Doutorado), Botucatu.

Herridge, D. F., \& Danso, S. K. A. (1995). Enhancing crop legume N2 fixation through selection and breeding. Plant Soil, $174,51-82$.

Hodge, A., Robinson, D., Griffiths, B. S., \& Fitter, A. H. (1999). Why plants bother: root proliferation results in increased nitrogen capture from an organic patch when two grasses compete. Plant, Cell and Environment, Chichester, 22, 811-820.

Hungria, M., Campo, R. J., Mendes, I. C. (2007). A importância do processo de fixação biológica do nitrogênio para a cultura da soja: componente essencial para a competitividade do produto brasileiro. Londrina-PR: Embrapa Soja, 80 p. (Documentos, 283).

Jacob-Neto, J., Santos, A. V., Franco, A. A., \& Takeda, S. T. (1997). Soybean seed enrichment with molybdenum to supply the plant requirement. 11th Internacional Congresso n Nitrogen Fixation Abstracts, 1, 69.

Kappes, C., Wruck, F., Carvalho, M. A. C., \& Yamashita, O. M. (2008). Feijão comum: características morfo-agronômicas de cultivares. In: CONGRESSO NACIONAL DE PESQUISA DE FEIJÃO, 9., Campinas. Anais... IAC, p. 506-509.

Lemos, L. B., Filho, D. F., Camargo, M. B., \& Silva, T. R. B. L. (2003) Inoculação de rizóbio e adubação nitrogenada em genótipos de feijoeiro. Agronomia, v. 37 , n. 1 .

Malavolta, E., Vitti, G. C., \& Oliveira, S. A. (1997). Avaliação do estado nutricional das plantas: princípios e aplicações. (2a ed.), POTAFOS, 319 p.

Marcarello, A., Yamashita, O. M., \& De Carvalho, M. A. C. (2012). Qualidade físiológica de sementes de feijoeiro em função da aplicação foliar de cobalto e molibdênio. Global Science And Technology, 5(2).

Martins, L. M., Xavier, G. R., Rangel, F. W., Ribeiro, J. R. A., Neves, M. C. P., Morgado L. B., \& Rumjanek, N. G. (2003). Contribution of biological nitrogen fixation to cowpea: a strategy for improving grain yield in the semi-arid region of Brazil. Biology and Fertility of Soils, $38(6)$ : 333-339.

Mercante, F. M., Franco, A. A., \& Munns, D. N. (1992). A inoculação do feijoeiro comum com rizóbio. Seropédica: Embrapa-CNPAF, (Comunicado Técnico, $10)$.

Moraga, F. G. (2018). Adubação foliar com cobalto e molibdênio na cultura da soja. Instituto de ciências agrárias e ambientais curso de agronomia. Trabalho de conclusão de curso (Graduação), Sinop.

Oliveira, C. A. B., De Mello, P. G., \& Pelá, A. (2017). Inoculação com Rhizobium tropici e adubação foliar com molibdênio na cultura do feijão comum. Journal of neotropical agriculture, 4(5), 43-50.

Paulo, F. S. D. (2013). Nodulação e desenvolvimento do feijão-caupi em função de diferentes doses de P, Co e Mo.

Pelegrin, R., Mervante, F. M., Otsubo, I. M. N., \& Otsubo, A. A. (2009). Resposta da cultura do feijoeiro à adubação nitrogenada e à inoculação com rizóbio. Revista Brasileira de Ciência do solo, 3(1), 219-226.

Robinson, D. (1994). The responses of plants to non-uniform supplies of nutrients. New Phytologist, Chichester, 127, 635-674.

Schossler, J. H., Meert, L., Rizzardi, D. A., \& Michalovicz, L. (2016). Componentes de rendimento e produtividade do feijoeiro comum submetido à inoculação e co-inoculação com estirpes de Rhizobium tropici e Azospirillum brasilense. Revista Scientia Agraria, Curitiba-PR, 17(1), 10-15.

Soares, A. G. (1996). Consumo e qualidade nutritiva. In: Reunião Nacional De Pesquisa De Feijão, 5., Goiânia. Anais... Goiânia: UFGO, 1996. 2, 73- 79.

Soares, A. L. L., Ferreira, P. A. A., \& Pereira, J. P. (2006). Eficiência agronômica de rizóbios selecionadose diversidade de populações nativas nodulíferas em Perdões (MG): II -feijoeiro. Revista Brasileira de Ciência Solo, 30, 750-758.

Telles, S. C. (2016) Rendimento de grãos do feijão sob diferentes doses de nitrogênio e inoculação de Rhizobium tropici. Universidade Tecnológica Federal do Paraná. Trabalho de conclusão de curso.

Torres, H. R. M., Ribeiro, P. R. C. C., \& Ribeiro, J. J. (2014). Produtividade do feijão phaseolus vulgaris 1 . com aplicações crescentes de molibdênio associadas ao cobalto via foliar. Enciclopédia biosfera, Centro Científico Conhecer. 10(18)..

Vieira, C. (2006). Adubação mineral e calagem. In: Vieira, C.; Paula Júnior, T. J.; Borém, A. (Eds.). Feijão. (2a ed.), UFV, $115-142$. 